\title{
Students' attitudes towards physics in Nine Years Basic Education in Rwanda
}

\author{
Agnes Mbonyiryivuze ${ }^{1}$, Lakhan Lal Yadav², Maurice Musasia Amadalo ${ }^{3}$ \\ ${ }^{1,2}$ African Centre of Excellence for Innovative Teaching and Learning Mathematics and Science (ACEITLMS), \\ University of Rwanda-College of Education (UR-CE), Rukara Campus, Rwanda \\ ${ }^{2}$ Department of Mathematics, Science and Physical Education, UR-CE, Rukara Campus, Rwanda \\ ${ }^{3}$ Kaimosi Friends University College (KAFUCO), Kenya
}

\begin{tabular}{l}
\hline \hline Article Info \\
\hline Article history: \\
Received Nov 2, 2020 \\
Revised Mar 17, 2021 \\
Accepted Apr 19, 2021 \\
\end{tabular}

Keywords:

Physics concept understanding Physics problem-solving Rural school Students' attitudes

Urban school

\begin{abstract}
This study investigated students' attitudes towards physics in Nine Year Basic Education (9YBE) in Rwanda. Data were collected from 380 students from Kayonza and Gasabo Districts using a physics attitudes test. Findings illustrated that more than a quarter of participants felt that learning physics is boring. About 39\% think that the subject of physics does not relate to the real-world experience. A significant number of participants had negative attitudes towards physics in terms of the effort required for learning. The findings also showed that the overall level for participants in physics problem-solving skills was low. The item-by-item analysis showed that the differences between responses of students from rural schools and their counterparts from urban schools in categories of problem-solving and physics concepts connections and understanding are statistically significant. It was found that many students in rural schools need to know more about the interpretation of a new equation to be able to apply it to a new physics problem.
\end{abstract}

This is an open access article under the CC BY-SA license.

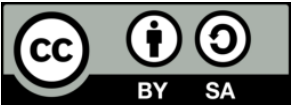

\section{Corresponding Author:}

Agnes Mbonyiryivuze

African Centre of Excellence for Innovative Teaching and Learning Mathematics and Science

University of Rwanda-College of Education (UR-CE)

Rukara Campus, PO BOX 55 Rwamagana, Rwanda

Email: mbonyiryivuzeagnes@yahoo.com

\section{INTRODUCTION}

In many nations, there is a pressing need to increase the number of students studying science subjects. As a result, countries are scrambling to meet the anticipated demand for more scientists, engineers, and doctors in order to overcome under-representation and foster equality [1]. In raising qualified manpower, countries will be able to compete on global scale and keep up with rapid advances in science and technology [2]. The Government of Rwanda is putting effort in building science and technology capacity to develop people within a prosperous knowledge-based and technology-led economy [3]. The current Rwandan educational policy fosters 9YBE consisting of six years of primary education and lower secondary education [4]. This aims at raising the population's general level of literacy, expertise, and skills, which has the potential to reduce poverty and boost future economy. In terms of enrolment and completion, 9YBE will result in universal primary education [4]. Physics is one of the compulsory science subjects at the Rwandan lower secondary level. After finishing the lower secondary level, students go into different fields including science having some options with physics. Those options may further lead to basic science subjects (with physics) including mechanical engineering, construction engineering, medicine, and information and 
communication technology (ICT) [3]. One dynamic branch of science is physics and it is considered essential to the creation of a knowledge-based society and the promotion of science and technology, which students will need in order to compete in global and regional job markets [3].

Despite the importance of physics for the development of Rwanda, physics education is facing some challenges including low students' performance, negative attitudes towards the subject [5]. Research has reported a low number of students decide to pursue physics as non-compulsory subject in high school and university [5]. For both teachers and students, the process of teaching and learning physics abstract concepts may be challenging [6]. Some teachers pointed out that some students fail physics because of their pessimistic attitude and lack of interest in the topic [7]. Students' negative attitudes towards physics are attributed to the fact that students consider the subject as a difficult, unattractive, boring, and abstract subject [7], [8]. Female students believe that that physics is difficult for them because it favors male-dominated natural science subjects [7]. Students' poor enrolment in physics compared to other science subjects and their low performance in the subject matter were reported at the College of Science and Technology, University of Rwanda to be caused by their negative attitude towards physics [5]. These findings were in agreement with results found that the increase of students' achievements is linked with their positive attitude towards physics [7]. Therefore, it is important to investigate students' attitudes towards physics at an early stage in order to facilitate the provision of solutions to improve their attitudes towards this subject matter.

Interest, satisfaction, motivation, self-related values, emotional influences, and perceived challenge are just a few of the sub-constructs that make up attitude [9], [10]. Attitude has been reported as one thing to think about when doing learning exercises [11]. Students with a positive attitude are more attentive in their learning and achieve satisfactory results, while students with a negative attitude are less diligent in their learning and achieve unsatisfactory results [12]. Some students' attitudes are thought to be critical in learning and separating novices from experts in a field. Some expert-attitudinal characteristics are viewing problemsolving as a conceptually based quest through the knowledge base rather than a hunt for equations, and physics should be viewed as a coherent, linked group of topics [13]. Studies have shown that students' attitudes include their perceptions of the coherence of physics understanding, the importance of the physics they study in class to the real world, and the relationship between mathematical equations and physics concepts, among other things [14], [15].

Physics curriculum planners and teachers cannot ignore students' attitudes as one important aspect for a curriculum to be successful is to improve students' attitudes towards physics [16]. Research indicated the interconnectedness of students' behaviors, cognitive abilities, and academic performance [17] and a positive correlation between students' attitudes and conceptual learning gains was reported [18]. Moreover, students' attitudes are influenced by teaching practices [18] and are shaped by their classroom experience [19]. Students' negative attitudes toward the discipline can have a negative impact on their academic performance [20]. Students' negative attitudes toward physics have translated into low enrolment in high school and, as a result, in university physics classes, resulting in fewer students pursuing and persisting in physics-related careers during their undergraduate degree [20]. Sufficient pieces of evidence show that when teacher pays attention to the knowledge and beliefs that students bring to learning assignment and use this as the starting point for new teaching, they may enhance their learning and conceptual change [21]. According to research, courses that use a range of interactive pedagogical techniques, such as Physics and Everyday Thinking [22], Modeling Instruction [13], [23], Physics through Inquiry [15], and Peer Instruction [24], result in a substantial positive student attitude benefit. Peer Instruction (PI) in introductory physics classes strengthened students' perceptions and beliefs about physics as well as their learning, according to a study conducted in China [24].

Students' attitudes towards rapidly changing technological environment will influence their ability to cope with it emotionally as well as in material ways. Therefore, an investigation on students' attitudes towards physics and recommendations on ways of improving their attitudes towards physics, enrolment in physics and their performance in the subject matter is important. Despite several studies in advanced countries on the students' attitudes towards physics, this study investigated students' attitudes towards physics in a Sub-Saharan developing country. It focuses only on senior two (S2) students' attitudes towards physics in selected 9YBE schools from Rwandan Eastern Province and Kigali city. The study also investigated whether average students' responses to survey items differed depending on their gender and school location.

\section{RESEARCH METHOD}

Students' attitudes toward physics in selected Rwandan secondary schools were investigated using a descriptive survey study design. A descriptive research design is a fundamental research design that looks at the situation as it is right now. It entails the observational detection of characteristics of a particular 
phenomenon or the investigation of the association between two or more phenomena [25]. This design method was adopted for this study as its purpose was describing and analysing the existing conditions of students' attitudes towards physics.

\subsection{Research participants}

The population of the study was 801 students composed of all senior two students from eighty schools from two districts from Eastern Province (Kayonza District) and Kigali city (Gasabo District). The sample for the study was drawn from those eight 9YBE and selected students have some experience with the new Rwandan secondary physics CBC that is under implementation [3]. They are also expected to have an idea about the options of their choice at the advanced secondary level. Senior two classes are chosen purposively because, at this level, students start to think about what major subjects they will choose at the end of their senior three (S3). The districts' choice was done to compare students' attitudes towards physics between rural and urban 9YBE schools. The sample comprises of 380 physics students. In terms of gender, it comprises of $208(54.7 \%)$ females and $172(45.3 \%)$ males. From the locational point of view, $179(47.1 \%)$ students were from rural schools while 201(52.9\%) from urban schools.

\subsection{Data collection}

Data collection was done through an attitude measuring scale called the Students' Physics Attitudes Test (SPAT). This instrument was designed by using existing surveys such as the Colorado Learning Attitudes about Science Survey (CLASS) [19], the Maryland Physics Expectations survey (MPEX) [26], and the Physics Attitude Scale (PAS) [27]. The aim of this survey was to find out how students felt about physics in terms of their interest and linking physics to the real world. Questions related to students' attitudes towards the effort put in learning physics, problem-solving, and conceptual connection and understanding are also included. A five-point scale ranged from point $1=$ strongly disagree (SD), $2=$ disagree (D), $3=$ Neutral $(\mathrm{N})$, 4=agree (A) to 5=strongly agree (SA). Three of twenty-two items are related to personal interest, five are related to make the link between physics and the real world, and the other five are related to the effort of learning physics. Moreover, the other three of twenty-two items are related to problem-solving and the remaining six items are related to conceptual connection and understanding. All used items for these five categories are reported in the section of results and discussions.

The reliability analysis from data obtained from a pilot study and validation were carried out before administering the questionnaire. The randomly chosen S2 of 9YBE was involved in the pilot study and it was not among the schools participated in the study with 28 participants. The piloted instrument had 28 items with five choices each. The instrument's reliability was determined using the Cronbach's alpha method and scores obtained from the responses of twenty-eight students. From the reliability analysis, six items that were inconsistent with others had been removed and the reliability coefficient reached at Cronbach alpha of 0.723 . The used questionnaire contained demographic data including school location, sex, and age. Factor analysis was not conducted as our sample was small [28]. An item's minimum score is one, and its maximum score is five. Experts in science education helped test the 22 -item attitude scale for material validity.

\subsection{Data analysis}

Data collected via questionnaires from 380 students was analyzed using both descriptive and inferential statistics in Statistics Package for Social Studies (SPSS). Descriptive statistical analysis was used to display the relative proportion of each degree of agreement with each attitude in the form of percentage tables. Moreover, an independent T-test was used to investigate the students' attitudinal differences based on gender and school location. Since statistical significance alone does not communicate the magnitude of group contribution to the difference, the effect size $\mathrm{d}$ was calculated. Cohen's $\mathrm{d}$ was calculated for the independent samples T-test by dividing the mean difference between two groups by the pooled standard deviation.

$$
\text { Cohen's } d=\frac{M_{1}-M_{2}}{D S_{\text {pooled }}} \text { where } D S_{\text {pooled }}=\sqrt{\left(\left(D S_{1}^{2}+D S_{2}^{2}\right) / 2\right)}
$$

M1 and M2 are means of two groups while DS1 and DS2 are their respective standard deviations. This formula has been recommended by Cohen to calculate the effect sizes of independent sample T-test for groups having almost the same size [29].

\section{RESULTS AND DISCUSSION}

This section provides results from descriptive and inferential statistical analyses. It starts with the results of students' attitudes towards physics learning in terms of their personal interest, applying physics in 
real-life situation to be accompanied by the time and effort taken to learn physics. This section is ended with the results of students' attitudes towards problem-solving in physics as well as students' attitudes towards physics conceptual connection and understanding.

\subsection{Students' personal interest towards physics}

Participants' responses to three statements investigating their personal interest in learning physics are shown in Table 1. The investigated attitudes include how enjoyable learning physics is, the significance of physics in daily life, as well as the value of understanding physics for all. Most of the participants (about $94 \%$ ) agreed that physics is important in everyday life. Moreover, about $86 \%$ claimed that physics is useful for everyone. Despite students' awareness of the importance of physics and their interest in the subject matter, a considerable number of participants at the rate of $23 \%$ claimed that learning physics is not fun. This shows that the overall interest was not high especially on the item investigating students' level of enjoyment in learning physics. This low interest in physics may affect students' effort to study the subject matter leading to poor performance and a negative attitude towards the subject matter. It was found that students who devote more time to learning physics are more likely to see physics as more important to their own lives [19]. Research found that the alarming decrease in physics academic achievement was mainly caused by students' attitudes towards physics [30]. Students' interest in physics was found to be among factors influencing them to pursue a degree in physics [31]. An independent sample T-test analysis was conducted to see if there were any differences in average student responses to the survey items based upon the gender and the location of the school. The null hypothesis in the test is that the average scores in each category are the same i.e., males and females and respondents from rural and urban schools. The significance level for this study is set to $\alpha=0.05$. The results of gender-based responses distribution for students' attitudes toward physics in terms of their personal interests are shown in Table 2.

Table 1. Students' personal interest towards physics

\begin{tabular}{clccc}
\hline $\begin{array}{c}\text { Item } \\
\text { no }\end{array}$ & \multicolumn{1}{c}{ SPAT items } & Agree & $\begin{array}{c}\text { Percentages } \\
\text { Neutral }\end{array}$ & Disagree \\
\hline 1 & Learning physics is fun & 63.57 & 8.24 & 22.87 \\
2 & Physics is important in everyday life & 94.19 & 2.11 & 3.69 \\
3 & Knowledge of physics is useful for everyone & 86.49 & 6.76 & 10.27 \\
\hline
\end{tabular}

Table 2. Gender statistics and t-test results for students' personal interest towards physics

\begin{tabular}{clccccccc}
\hline Item no & Gender & $\mathrm{N}$ & Mean & SD & T & df & p-value & Cohen's d \\
\hline 1 & Male & 171 & 3.44 & 1.389 & 1.309 & 374 & 0.191 & 0.14 \\
& Female & 205 & 3.64 & 1.549 & & & & \\
2 & Male & 171 & 4.49 & 0.884 & 0.798 & 377 & 0.425 & 0.08 \\
& Female & 208 & 4.56 & 0.849 & & & & \\
3 & Male & 168 & 4.33 & 0.912 & 0.418 & 368 & 0.676 & 0.04 \\
& Female & 202 & 4.37 & 1.077 & & & & \\
\hline
\end{tabular}

*SD=Standard Deviation

Since certain questions have a few blank responses, the total number of students $\mathrm{N}$ varies from question to question. The findings indicate that there was no discernible difference in gender as indicated by the closeness of mean values for both female and male respondents for all items. These results are supported by those from the independent sample T-test. The findings of this test also revealed that there is no statistically significant difference between male and female students' attitudes towards physics in terms of their personal interest. The $p$-values for all items are greater than the significance level $(\alpha=0.05)$ and the effect was too small for all items $(\mathrm{d}<0.2)$. These findings show that there is no substantial difference in interest in physics among students based on gender. These results are not in agreement with the study conducted by Veloo, Nor, and Khalid [7] in Malaysia. For this study, it was found that there was a significant difference in students' interest towards physics in terms of gender where male students were higher compared to female students [7]. In the United States of America, it was found that women's personal interest ratings are lower than men's for all surveyed courses [19]. Despite the disagreement between the result of this study and those from Veloo, Nor, and Khalid [7], Perkins, et al. [19], obtained results are in good agreement with those found by Mushinzimana and Sinaruguliye [5] in Rwanda. While studying students' attitudes towards physics at the College of Science and Technology of University of Rwanda, the authors found that gender did not influence students' attitudes towards physics [5]. The group statistics of respondents in terms of their school locations and t-test results for students' interest towards physics are reported in Table 3. 
Table 3. School location statistics and t-test results for students' personal interest towards physics

\begin{tabular}{clccccccc}
\hline Item no & District & $\mathrm{N}$ & Mean & SD & $\mathrm{T}$ & $\mathrm{df}$ & $\mathrm{p}$-value & Cohen's d \\
\hline \multirow{2}{*}{1} & Rural & 177 & 3.67 & 1.429 & 1.476 & 372.83 & 0.141 & 0.16 \\
& Urban & 199 & 3.44 & 1.519 & & & & \\
2 & Rural & 178 & 4.55 & 0.774 & 0.428 & 377 & 0.669 & 0.05 \\
& Urban & 201 & 4.51 & 0.939 & & & & \\
3 & Rural & 177 & 4.51 & 0.867 & 2.940 & 360.12 & 0.003 & 0.30 \\
& Urban & 193 & 4.21 & 1.099 & & & & \\
\hline
\end{tabular}

There was a statistically significant difference discovered for the third item probing about students' awareness of the usefulness of physics for everyone. A significant difference between respondents from rural schools and urban schools with the corresponding $\mathrm{p}$-value $\mathrm{p}=0.003$ and small effect size $\mathrm{d}=0.30$ was obtained. These findings reveal a disparity in students' attitudes toward physics in terms of appreciating the value of physics expertise for all. Students from rural schools appreciate more the importance of knowing physics for everyone more than students from urban schools. According to the findings, students' interest in physics seems to be linked to them redefining what physics problems are, how problem-solving relates to the self, and that physics is a part of their daily lives [22]. Thus, finding ways to improve students' interest towards physics will affect their problem solving that may lead to high performance in the subject matter.

\subsection{Students' ability to link physics to the real world}

The percentages of students' responses to survey statements regarding their attitudes toward physics in terms of their ability to link physics to the real world are displayed in Table 4 . The findings show that about $74 \%$ of physics students agreed that learning physics aids them in making sense problems that arise in their daily lives; $84 \%$ of them agreed that their thinking skills, which they use to understand physics, can be beneficial in their daily lives and about $74 \%$ claimed that the laws of physics are related to what they see in the real world. About $58 \%$ of participants claimed that in order to comprehend physics, they often reflect on personal experiences and apply them to the subject at hand. About 50\% of participants claimed that physics is closely related to what they see and encounter in the physical world while about half of them thought otherwise. A big number of students (about 39\%) think that the subject of physics has little relation to what they experience in the real world. It is clear that most of the students think that physics is linked to everyday life, but a big number of them cannot link their experiences when they learn physics. It appears that many students can link physics and their everyday experiences at a superficial level. The obtained difference in scores between male and female respondents in personal interest and ability to connect physics to the real world is in good agreement with previous research [19]. Table 5 indicates gender-based group statistics for respondents and t-test findings to find out how they feel about physics in terms of their ability to link physics to the reality.

The findings show that only the first two elements in this group have a statistically relevant gender gap. Those two first items are about the use of learning physics in helping to understand situations in students' everyday life and if reasoning skills used to understand physics can be helpful in their everyday life. For the first item, there was a statistically significant difference between males and females with the corresponding $p$-value $p=0.043$. For the second item, there was a significant difference between male and female respondents with the corresponding $p$-value $p=0.011$. The small effect sizes $\left(d_{1}=0.21\right.$ and $\left.d_{2}=0.26\right)$ have been observed for these two first items.

Table 6 indicates group statistics of respondents' answers in terms of their school location and t-test results for students' attitudes towards physics in terms of linking physics to the real world. Only the third and fourth items showed a statistically significant difference for this category. There was a statistically significant difference between respondents from rural and urban schools for the third question with a $p$-value of $p=0.01$ and a small effect size of $\mathrm{d}=0.26$. While for the fourth item, there was also a significant difference between respondents from rural and those from urban schools with the corresponding $p$-value $p=0.024$ and small effect size $d=0.24$. This shows that the difference in students' attitudes in terms of linking physics to the real world was realized in terms of school locations for these two items measuring how students relate physics laws to what they experience in the real world and whether they use their personal experiences to understand physics topics. 
Table 4. Students' attitudes in terms of linking physics to the real world

\begin{tabular}{|c|c|c|c|c|}
\hline \multirow{2}{*}{$\begin{array}{c}\text { Item } \\
\text { no }\end{array}$} & \multirow{2}{*}{ SPAT items } & \multicolumn{3}{|c|}{ Percentages } \\
\hline & & Agree & Neutral & Disagree \\
\hline 1 & Learning physics helps me understand situations in my everyday life & 73.85 & 15.36 & 10.78 \\
\hline 2 & Reasoning skills used to understand physics can be helpful in my everyday life & 83.74 & 6.40 & 9.87 \\
\hline 3 & Physics laws have a relation to what I experience in the real world & 73.94 & 10.26 & 14.74 \\
\hline 4 & $\begin{array}{l}\text { To understand physics, I sometimes think about my personal experiences and } \\
\text { relate them to the topic being analyzed }\end{array}$ & 57.52 & 15.57 & 26.91 \\
\hline 5 & The subject of physics has little relation to what I experience in the real world & 39.26 & 10.34 & 49.87 \\
\hline
\end{tabular}

Table 5. Gender statistics and t-test results for students' attitudes in terms of linking physics to the real world

\begin{tabular}{|c|c|c|c|c|c|c|c|c|}
\hline Item no & Gender & $\mathrm{N}$ & Mean & $\mathrm{SD}$ & $\mathrm{T}$ & $\mathrm{df}$ & p-value & Cohen's d \\
\hline \multirow[t]{2}{*}{1} & Male & 171 & 3.79 & 1.169 & 2.028 & 335.22 & 0.043 & 0.21 \\
\hline & Female & 200 & 4.02 & 0.992 & & & & \\
\hline \multirow[t]{2}{*}{2} & Male & 170 & 4.04 & 1.117 & 2.559 & 373 & 0.011 & 0.26 \\
\hline & Female & 205 & 4.32 & 1.007 & & & & \\
\hline \multirow[t]{2}{*}{3} & Male & 172 & 3.84 & 1.241 & 0.901 & 378 & 0.368 & 0.09 \\
\hline & Female & 208 & 3.95 & 1.231 & & & & \\
\hline \multirow[t]{2}{*}{4} & Male & 172 & 3.47 & 1.268 & 0.133 & 377 & 0.894 & 0.01 \\
\hline & Female & 207 & 3.48 & 1.336 & & & & \\
\hline \multirow[t]{2}{*}{5} & Male & 171 & 3.02 & 1.475 & 0.133 & 375 & 0.079 & 0.18 \\
\hline & Female & 206 & 2.75 & 1.541 & & & & \\
\hline
\end{tabular}

Table 6. School location statistics and t-test results on students' attitude in terms of linking physics to the real

\begin{tabular}{|c|c|c|c|c|c|c|c|c|}
\hline \multicolumn{9}{|c|}{ world } \\
\hline Item no & District & $\mathrm{N}$ & Mean & SD & $\mathrm{T}$ & $\mathrm{df}$ & p-value & Cohen's d \\
\hline \multirow[t]{2}{*}{1} & Rural & 175 & 3.97 & 1.096 & 0.970 & 369 & 0.333 & 0.10 \\
\hline & Urban & 196 & 3.86 & 1.070 & & & & \\
\hline \multirow[t]{2}{*}{2} & Rural & 175 & 4.18 & 1.097 & 0.297 & 373 & 0.766 & 0.03 \\
\hline & Urban & 200 & 4.21 & 1.040 & & & & \\
\hline \multirow[t]{2}{*}{3} & Rural & 179 & 4.07 & 1.254 & 2.590 & 378 & 0.010 & 0.26 \\
\hline & Urban & 201 & 3.75 & 1.200 & & & & \\
\hline \multirow[t]{2}{*}{4} & Rural & 179 & 3.64 & 1.444 & 2.272 & 339.17 & 0.024 & 0.24 \\
\hline & Urban & 200 & 3.33 & 1.148 & & & & \\
\hline \multirow[t]{2}{*}{5} & Rural & 178 & 2.72 & 1.477 & 1.867 & 375 & 0.063 & 0.19 \\
\hline & Urban & 199 & 3.01 & 1.541 & & & & \\
\hline
\end{tabular}

\subsection{The effort and time needed to learn physics}

The percentages of the answers to survey statements about the attitudes of physics students' attitudes towards the effort and time needed to learn physics are displayed in Table 7 . It was found that $95 \%$ of participated students agreed that if they study hard enough, almost everyone can understand physics. $62 \%$ of participants agreed that they read the text carefully and work through a variety of examples that demonstrate physics concepts. Moreover, 65\% claimed that they apply relevant knowledge to what they already know rather than memorizing it as it is introduced while learning physics. $56 \%$ of participants claimed that if they are unable to solve a problem in less than 10 minutes then they keep trying while $39 \%$ said they give up and leave the problem. Those students believing that they should give up on solving problems within 10 minutes are unlikely to persist in their efforts to learn more techniques for resolving difficult problems [32]. 86\% of participants claimed while learning physics, they may be satisfied even if they don't understand why anything operates in a certain way. From these findings, it is clear that many participants had positive attitudes towards the effort required and put in learning physics, however, a significant number of participants have negative attitudes towards physics in terms of the effort required and put in learning. Finding from the last item, where $86 \%$ claimed to be satisfied even if they don't understand why anything operates in a certain way, shows the tendency of memorizing without understanding well the subject matter. Students acknowledge that to make sense of physics problems, trying and working hard are required and these findings are consistent with previous results [33]. However, it seems that many of them put effort in memorization without understanding. The distribution of gender-based students' responses by mean scores, standard deviations, and t-test results on students' attitudes toward physics in terms of the effort and time needed to learn the subject is shown in Table 8. 
Table 7. Students' attitudes towards physics in terms of the effort and time needed to learn physics

\begin{tabular}{|c|c|c|c|c|}
\hline \multirow{2}{*}{$\begin{array}{l}\text { Item } \\
\text { no }\end{array}$} & \multirow{2}{*}{ SPAT items } & \multicolumn{3}{|c|}{ Percentages } \\
\hline & & Agree & Neutral & Disagree \\
\hline 1 & If they study hard enough, almost everyone can understand physics. & 95.26 & 2.11 & 2.63 \\
\hline 2 & $\begin{array}{l}\text { I thoroughly read the text and worked through many realistic examples that } \\
\text { demonstrate physics concepts }\end{array}$ & 61.84 & 17.37 & 20.79 \\
\hline 3 & $\begin{array}{l}\text { Instead of memorizing essential knowledge in physics the way it is } \\
\text { presented, I relate it to what I already know }\end{array}$ & 65.43 & 10.29 & 23.48 \\
\hline 4 & If I cannot solve a problem within 10 minutes then I give up and leave it & 39.31 & 4.22 & 55.93 \\
\hline 5 & I'm not happy until I've figured out why anything works the way it does & 7.38 & 5.8 & 86.28 \\
\hline
\end{tabular}

Table 8. Gender statistics and t-test results on students' attitude towards the effort put and required to learn physics

\begin{tabular}{|c|c|c|c|c|c|c|c|c|}
\hline Item no & Gender & $\mathrm{N}$ & Mean & $\mathrm{SD}$ & $\mathrm{T}$ & $\mathrm{df}$ & p-value & Cohen's d \\
\hline \multirow[t]{2}{*}{1} & Male & 172 & 4.56 & 0.781 & 1.419 & 329.14 & 0.157 & 0.14 \\
\hline & Female & 208 & 4.66 & 0.639 & & & & \\
\hline \multirow[t]{2}{*}{2} & Male & 172 & 3.58 & 1.195 & 0.874 & 378 & 0.383 & 0.08 \\
\hline & Female & 208 & 3.68 & 1.186 & & & & \\
\hline \multirow[t]{2}{*}{3} & Male & 171 & 3.82 & 1.134 & 2.623 & 376.74 & 0.009 & 0.26 \\
\hline & Female & 208 & 3.48 & 1.417 & & & & \\
\hline \multirow[t]{2}{*}{4} & Male & 171 & 2.78 & 1.697 & 1.082 & 377 & 0.280 & 0.11 \\
\hline & Female & 208 & 2.59 & 1.645 & & & & \\
\hline \multirow[t]{2}{*}{5} & Male & 171 & 1.75 & 0.981 & 1.204 & 377 & 0.229 & 0.12 \\
\hline & Female & 208 & 1.63 & 0.949 & & & & \\
\hline
\end{tabular}

From the conducted independent sample T-test, there is no discernible distinction between males and females' attitudes towards physics in terms of the effort required or put in learning physics. Only the statistically significant difference was for the third item measuring how respondents rather than memorizing new material, they can connect it to what they already know while studying physics with the corresponding $p$-value $p=0.009$ and small effect size $d=0.26$. For this item, males scored higher compared to females. This shows that female students have more tendency to memorize compared to male students. Both descriptive and inferential analysis shows that students tend to memorize the subject matter without understanding well. This is in good agreement with another study carried out in Rwanda [34]. It was reported that students' observations of the environment contribute to the formation of several new ideas on how the world works. Often, the concepts held by many students do not match with those being taught in physics courses [35]. Holding these preconceptions, it may be difficult for students to construct the desired inferences by the teacher. However, it has been shown that, when this condition is considered, it is possible to have activities that encourage the majority of students to gain a strong practical understanding of many of the basic physics concepts [26], [36]. Previous research shows that students' attitudes towards a subject can influence their motivation and adopted approaches to study the subject matter [37].

Table 9 shows group statistics of respondents in terms of their school location t-test results for students' attitudes towards physics in terms of the effort put and required in learning physics. Only the third item showed a statistically significant difference between respondents from rural and those from urban with the corresponding $\mathrm{p}$-value $\mathrm{p}=0.004$ and small effect size $\mathrm{d}=0.30$. Respondents from rural schools showed a greater tendency of relating the important information to what they already know rather than just memorizing when studying physics comparing to those from urban schools.

Table 9. School location statistics and t-test results on students' attitude towards the effort put and required to learn physics

\begin{tabular}{clllllllc}
\hline Item no & District & $\mathrm{N}$ & Mean & $\mathrm{SD}$ & $\mathrm{T}$ & $\mathrm{df}$ & $\mathrm{p}$-value & Cohen's d \\
\hline \multirow{2}{*}{1} & Rural & 179 & 4.65 & 0.583 & 1.001 & 363.73 & 0.317 & 0.10 \\
& Urban & 201 & 4.58 & 0.803 & & & & \\
2 & Rural & 179 & 3.69 & 1.172 & 0.818 & 378 & 0.414 & 0.08 \\
& Urban & 201 & 3.59 & 1.206 & & & & \\
\multirow{2}{*}{3} & Rural & 179 & 3.84 & 1.157 & 2.906 & 374.41 & 0.004 & 0.30 \\
& Urban & 200 & 3.46 & 1.406 & & & & \\
& Rural & 179 & 2.66 & 1.594 & 0.180 & 376.77 & 0.857 & 0.02 \\
& Urban & 200 & 2.69 & 1.738 & & & & 0.09
\end{tabular}




\subsection{Students' attitude towards problem-solving in physics}

Students' attitudes and approaches to physics problem solving have an effect on their ability to learn physics and how good they are at solving physics problems [38]. Therefore, data from a survey on students' attitudes toward physics problem solving were analysed and findings are shown in Table 10.

Table 10. Students' attitudes towards problem-solving in physics

\begin{tabular}{|c|c|c|c|c|}
\hline \multirow{2}{*}{$\begin{array}{c}\text { Item } \\
\text { no }\end{array}$} & \multirow{2}{*}{ SPAT items } & \multicolumn{3}{|c|}{ Percentages } \\
\hline & & Agree & Neutral & Disagree \\
\hline 1 & $\begin{array}{l}\text { To use an equation in a problem (especially one I've never seen before), I need to know } \\
\text { more than just what of word in the equation means }\end{array}$ & 79.1 & 11.38 & 9.52 \\
\hline 2 & $\begin{array}{l}\text { Finding the right equation to use is the most important part of solving a physics } \\
\text { problem }\end{array}$ & 92.64 & 4.21 & 3.16 \\
\hline 3 & $\begin{array}{l}\text { In physics, problem-solving entails matching problems with facts or equations, then } \\
\text { plugging in values to get a number }\end{array}$ & 87.26 & 6.90 & 5.83 \\
\hline
\end{tabular}

The investigated issues were about the need to know more than what each term means in the new equation to be able to apply it in a new physics problem that they haven't seen before. It was found that $79 \%$ of respondents agreed that to be able to use an equation in a problem, they need to know more than what each term means in the equation. About $93 \%$ of respondents agreed that finding the right equation to use is the most important part of solving a physics problem. Moreover, $87 \%$ of respondents claimed that physics, problem-solving entails matching problems with facts or equations, then plugging in values to get a number. These findings show that the overall level for participated students' from 9YBE in physics problem-solving skills is low. The obtained results are also supported by those obtained from T-test analysis. These findings are consistent with those obtained by Otero and Gray [22]. According to their pre-surveys, students thought of solving physics problems as a process of formulaic manipulation and memorization to arrive at a predetermined response [22].

As indicated by Table 11, a statistically significant difference has been observed for the only second item of this category while comparing gender by using the T-test. The observed statistical significant difference between male and female participants has the corresponding $p$-value $p=0.003$ and small effect size $\mathrm{d}=0.31$. These findings indicated that most of the participants had negative attitudes toward problem-solving in physics. This was observed on the item investigating students' level of agreement on whether the most important thing in solving a physics problem is to find the right equation to use. More females believed that finding the right equation to use is the most important part of solving a physics problem. The research reported that a lack of problem-solving skills may lead to poor students' attitudes toward physics [8]. To solve a physics problem effectively, students have to decide what conceptual knowledge to use for each smaller problem and the needed unknown information to complete each problem part. This process may only be possible if the student organizes and learn to access conceptual knowledge in an organized structure [20]. The group statistics of respondents in terms of their school location and T-test results for students' attitudes towards physics problem-solving are also reported in Table 12.

Table 11. Gender statistics and t-test results for students' attitudes towards physics problem solving

\begin{tabular}{ccccccccc}
\hline No & Gender & N & Mean & SD & T & df & p-value & Cohen's d \\
\hline 1 & Male & 170 & 4.16 & 1.001 & 0.710 & 376 & 0.478 & 0.07 \\
& Female & 208 & 4.09 & 1.113 & & & & \\
2 & Male & 172 & 4.36 & 0.850 & 2.946 & 334.90 & 0.003 & 0.31 \\
& Female & 208 & 4.60 & 0.715 & & & & \\
3 & Male & 171 & 4.26 & 0.929 & 0.709 & 375 & 0.479 & 0.08 \\
& Female & 206 & 4.33 & 0.924 & & & & \\
\hline
\end{tabular}

Table 12. School location and T-test results for students' attitudes towards physics problem-solving

\begin{tabular}{ccccccccc}
\hline Item no & District & $\mathrm{N}$ & Mean & SD & T & df & p-value & Cohen's d \\
\hline 1 & Rural & 179 & 4.39 & 0.931 & 4.700 & 376 & 0.000 & 0.50 \\
& Urban & 199 & 3.88 & 1.120 & & & & \\
2 & Rural & 179 & 4.50 & 0.767 & 0.119 & 378 & 0.905 & 0.01 \\
& Urban & 201 & 4.49 & 0.807 & & & & \multirow{2}{*}{0.29} \\
3 & Rural & 178 & 4.44 & 0.795 & 2.879 & 375 & 0.004 & 0.29 \\
& Urban & 199 & 4.17 & 1.014 & & & & \\
\hline
\end{tabular}


The statistically significant differences were found for the first and third items. The first item was about the students' need to know more than what each term means in the new equation to be able to apply it in a new physics problem that they haven't seen before. For this item, there was a significant difference between respondents from rural and those from urban with the corresponding $p$-value $p=0.00$ and small effect medium $\mathrm{d}=0.50$. The third item was about the problem-solving in physics as matching problems with facts or equations and then putting values to get a number. For this item, there was a significant difference between respondents from rural and those from urban with the corresponding $\mathrm{p}$-value $\mathrm{p}=0.004$ and small effect size $\mathrm{d}=0.29$. Our results show that many students from rural schools believe that to be able to use an equation in a problem, they need to know more than what each term means in the equation. Moreover, many of them believe that problem-solving in physics means matching problems with facts or equations and then putting values to get a number.

\subsection{Students' attitude towards physics concepts connection and understanding}

The percentages of students who responded to statements in a survey about their attitudes toward physics concepts connection and understanding are displayed in Table 13. From the obtained results, it was found that about $81 \%$ of respondents agreed that physics consists of a coherent hierarchical structure of knowledge. About $69 \%$ of all respondents agreed that one of the most difficult aspects of studying physics is remembering what they need to know. Moreover, about $58 \%$ claimed that they anticipate that physics equations would aid their comprehension of a concept while about $33 \%$ said that physics equations are just for calculation. About $59 \%$ of respondents claimed that they have no trouble solving problems on the same subject after studying a topic in physics and feeling that they understand it, while $33 \%$ have difficulty solving problems on the same topic. About $48 \%$ agreed that if they get stuck on a physics problem, there's a chance they will figure it out on their own, while about $40 \%$ said there's no way they will figure it out on their own. Moreover, $60 \%$ of participants claimed that while they are unable to recall a specific equation used to solve a problem on an exam, still they can do something sincerely to come up with it. However, about $31 \%$ of participants claimed that there isn't something they can do honestly to recall a specific equation required to solve a problem on an exam if they don't remember it. This shows that a big number of the participants were novices viewing physics as a set of separate facts and formulas that must be memorized. These novices feel that these collections of isolated facts and formulas have nothing to do with reality. have little connection to the real world. This is consistent with some earlier studies [20]. It was argued that students will lose interest in physics if they cannot make strong links between what they study in class and how the world functions. This low interest may easy students to develop negative attitude towards physics leading them to choose other different areas [39]. Moreover, it was reported that students' assumptions and convictions about the essence of doing and understanding physics were related to their decision to study physics, according to reports [40]. Findings related to gender-based group statistics for respondents and T-test results for students' attitudes toward physics in terms of physics concepts connection and understanding are indicated in Table 14.

The study findings revealed a statistically significant difference for only the third item. This item was measuring students' expectations on physics equations to help their understanding of ideas or if they are just for calculation. There was a significant difference between males $(M=2.77)$ and females $(M=2.45)$ with the corresponding $p$-value $p=0.037$ and small effect size $d=0.22$. The independent sample $T$-test results show that there was no significant difference in terms of school location for all items as their p-values are greater than the significance level $(\alpha=0.05)$.

Table 13. Students' attitude towards physics concepts connection and understanding

\begin{tabular}{|c|c|c|c|c|}
\hline \multirow{2}{*}{$\begin{array}{c}\text { Item } \\
\text { no }\end{array}$} & \multirow{2}{*}{ SPAT items } & \multicolumn{3}{|c|}{ Percentages } \\
\hline & & Agree & Neutral & Disagree \\
\hline 1 & Physics consists of a coherent hierarchical structure of knowledge & 80.53 & 12.63 & 6.58 \\
\hline 2 & One of the most difficult aspects of studying physics is remembering what I need to know & 68.97 & 9.28 & 20.95 \\
\hline 3 & $\begin{array}{l}\text { I don't expect physics equations to help my understanding of a concept; they're just there } \\
\text { to help me calculate }\end{array}$ & 33.33 & 8.47 & 57.93 \\
\hline 4 & $\begin{array}{l}\text { After I've studied a chapter in physics and believe I've grasped it, I find it challenging to } \\
\text { solve problems on the same topic }\end{array}$ & 32.71 & 7.65 & 59.37 \\
\hline 5 & There's no way I'll be able to solve a physics problem on my own if I get stuck & 40.31 & 11.14 & 48.01 \\
\hline 6 & $\begin{array}{l}\text { There's nothing I can do honestly to recall an equation required to solve a problem on an } \\
\text { exam if I don't remember it }\end{array}$ & 30.68 & 9.26 & 60.05 \\
\hline
\end{tabular}

Int J Eval \& Res Educ, Vol. 10, No. 2, June 2021: 648 - 659 
Table 14. Gender statistics and t-test results on students' attitude towards physics concept connection and

\begin{tabular}{ccccccccc}
\multicolumn{8}{c}{ understanding } \\
\hline Item no & Gender & $\mathrm{N}$ & Mean & SD & T & df & p-value & Cohen's d \\
\hline 1 & Male & 172 & 4.24 & 0.971 & 0.407 & 378 & 0.684 & 0.04 \\
& Female & 208 & 4.20 & 0.995 & & & & \\
2 & Male & 171 & 3.66 & 1.460 & 1.286 & 341.35 & 0.199 & 0.13 \\
& Female & 206 & 3.84 & 1.282 & & & & \\
3 & Male & 170 & 2.77 & 1.511 & 2.095 & 376 & 0.037 & 0.22 \\
& Female & 208 & 2.45 & 1.437 & & & & \\
4 & Male & 171 & 2.58 & 1.475 & 0.688 & 377 & 0.492 & 0.07 \\
& Female & 208 & 2.47 & 1.554 & & & & \multirow{2}{*}{5} \\
5 & Male & 171 & 2.77 & 1.452 & 1.092 & 375 & 0.275 & 0.11 \\
& Female & 206 & 2.94 & 1.559 & & & & \\
6 & Male & 170 & 2.42 & 1.556 & 0.569 & 376 & 0.570 & 0.06 \\
& Female & 208 & 2.51 & 1.570 & & & & \\
\hline
\end{tabular}

Table 15 indicates school location statistics for respondents and t-test results for students' attitudes toward physics in terms of physics concepts connection and understanding. For this category, a statistically significant difference was observed for the third item only. Between respondents from rural and urban schools, there was a substantial difference with a $\mathrm{p}$-value of $\mathrm{p}=0.000$ and medium effect size of $\mathrm{d}=0.50$. Many students from rural schools believe that physics equations are just for calculation than those from urban schools. As educators, it is our responsibility to facilitate our students to use productively their cognitive resources and help them to choose the more productive approaches to learning that lead to better conceptual learning [41].

Table 15. School location statistics and t-test results on students' attitude towards physics concepts connection and understanding

\begin{tabular}{|c|c|c|c|c|c|c|c|c|}
\hline Item no & District & $\mathrm{N}$ & Mean & SD & $\mathrm{T}$ & $\mathrm{df}$ & p-value & Cohen's d \\
\hline \multirow[t]{2}{*}{1} & Rural & 179 & 4.29 & 1.003 & 1.400 & 378 & 0.162 & 0.14 \\
\hline & Urban & 201 & 4.15 & 0.963 & & & & \\
\hline \multirow[t]{2}{*}{2} & Rural & 178 & 3.74 & 1.387 & 0.340 & 375 & 0.734 & 0.03 \\
\hline & Urban & 199 & 3.78 & 1.352 & & & & \\
\hline \multirow[t]{2}{*}{3} & Rural & 177 & 2.98 & 1.522 & 4.822 & 354.98 & 0.000 & 0.50 \\
\hline & Urban & 201 & 2.26 & 1.354 & & & & \\
\hline \multirow[t]{2}{*}{4} & Rural & 179 & 2.37 & 1.472 & 1.839 & 377 & 0.067 & 0.19 \\
\hline & Urban & 200 & 2.66 & 1.549 & & & & \\
\hline \multirow[t]{2}{*}{5} & Rural & 177 & 2.71 & 1.501 & 1.788 & 375 & 0.075 & 0.19 \\
\hline & Urban & 200 & 2.99 & 1.514 & & & & \\
\hline \multirow[t]{2}{*}{6} & Rural & 178 & 2.40 & 1.497 & 0.814 & 376 & 0.416 & 0.08 \\
\hline & Urban & 200 & 2.53 & 1.619 & & & & \\
\hline
\end{tabular}

\section{CONCLUSION}

This study revealed that a considerable number of participants at a rate of $26 \%$ claimed that learning physics is not fun. About $39 \%$ believe that physics has nothing to do with what they see and experience in the real world. A significant number of participants have negative attitudes towards physics in terms of the effort required and put in learning the subject matter. The findings also show that the overall level for participants in physics problem-solving skills is low and that a big number of the participants were novices viewing physics as a set of facts and formulas to memorize. The results from the T-test revealed that in the total distribution, there were no statistically significant variations of students' attitudes towards physics for gender and school location. However, there are statistically important variations between the group averages on certain items within various categories on an item-by-item basis. The highest statistically significant differences were observed for school location groups' comparison in problem-solving, and physics concepts connections and understanding categories. Their corresponding $\mathrm{p}$-values and effect sizes are $\mathrm{p}=0.000$ and 0.50 respectively. The sample size and investigation performed only in 9YBE schools restrict the findings. Future investigation and analyses may be extended to a considerable number of other different schools to develop a more detailed understanding of students' attitudes towards physics and how these can influence their conceptual understanding and performance.

We strongly recommend using some interactive pedagogical approaches, which were found to provide significant attitudinal gains of physics students including Modeling Instruction and Peer Instruction in which teachers do not need costly laboratory and usually not available in rural areas of developing countries. Robust trainings for physics teachers on different interactive pedagogical strategies which have 
been proven to provide a positive shift in students' attitudes and beliefs about physics are needed. Due to inconsistency in the literature, there is a need for future studies investigating more carefully about gender differences in students' attitudes toward physics. Moreover, it would be beneficial to examine students' attitudes towards physics in different schools and universities, particularly attitudes of physics students coming from various countries to find out if their attitudes towards the subject matter depend on cultural context.

\section{ACKNOWLEDGEMENTS}

Financial support provided by the African Centre of Excellence for Innovative Teaching and Learning Mathematics and Science (ACEITLMS) is thankfully acknowledged.

\section{REFERENCES}

[1] R. Sheldrake, T. Mujtaba, and M. J. Reiss, "Students' changing attitudes and aspirations towards physics during secondary school," Research in Science Education, vol. 48, pp. 1809-1834, 2019, doi: 10.1007/s11165-017-9676-5.

[2] I. Benek and B. Akcay, "Development of STEM attitude scale for secondary school students: Validity and reliability study," International Journal of Education in Mathematics, Science and Technology, vol. 7, no. 1, pp. 32-52, 2019.

[3] REB, Ordinary level physics syllabus. Kigali, Rwanda: Rwanda Education Board, 2015. [Online]. Available: $\mathrm{http}: / /$ reb.rw/fileadmin/competence_based_curriculum/syllabi/Lower_Secondary/Physics.pdf

[4] MINEDUC and REB, Summary of curriculum frame-work: Pre-primary to upper secondary. Kigali, Rwanda: Ministry of Education, 2015. [Online]. Available: https://elearning.reb.rw/pluginfile.php/28040/mod_resource/ content/1/CURRICULUM_FRAMEWORK_FINAL.pdf

[5] X. Mushinzimana and J. D. Sinaruguliye, "Attitude of physics students towards physics at College of Science and Technology - University of Rwanda," The Rwandan Journal of Education, vol. 3, no. 2, pp. 1-10, 2016. [Online]. Available: https://www.ajol.info/index.php/rje/article/view/157206.

[6] T. Civelek, E. Ucar, H. Ustunel, and M. K. Aydın, "Effects of a haptic augmented simulation on K-12 students' achievement and their attitudes towards physics," Eurasia Journal of Mathematics, Science \& Technology Education, vol. 10, no. 6, pp. 565-574, 2014, doi: 10.12973/eurasia.2014.1122a.

[7] A. Veloo, R. Nor, and R. Khalid, "Attitude towards physics and additional mathematics achievement towards physics achievement," International Education Studies, vol. 8, no. 3, pp. 35-43, 2015. doi: 10.5539/ies.v8n3p35.

[8] N. Erdemir, "Determining students' attitude towards physics through problem-solving strategy," Asia-Pacific Forum on Science Learning and Teaching, vol. 10, no. 2, pp. 1-19, Dec. 2009. [Online]. Available: http://www.ied.edu.hk/apfslt/v10_issue2/erdemir/index.htm.

[9] M.S. Hannula, P. Di Martino, M. Pantziara, Q. Zhang, F. Morselli, E. Heyd-Metzuyanim, et al., "Attitudes, beliefs, motivation and identity in mathematics education," in ICME - 13 Topical Surveys. Springer, Cham, 2016, doi: 10.1007/978-3-319-32811-9.

[10] N. B. O'Connell, M. Dempsey, and A O'Shea, "An investigation of students' attitudes to science, mathematics and the use of technology in lower secondary education," International Journal of Education in Mathematics, Science and Technology, vol. 7, no. 4, pp. 319-334, 2019.

[11] J. Jufrida, W. Kurniawan, A. Astalini, D. Darmaji, D. A. Kurniawan, and W. A. Maya, "Students' attitude and motivation in mathematical physics," International Journal of Evaluation and Research in Education (IJERE), vol. 8, no. 3, pp. 401-408, 2019, doi : 10.11591/ijere.v8i3.20253.

[12] D.A. Kurniawan, A. Astalini, D. Darmaji, and R. Melsayanti, "Students' attitude towards natural sciences," International Journal of Evaluation and Research in Education (IJERE), vol. 8, no. 3, pp. 455-460, 2019, doi: 10.11591/ijere.v8i3.16395.

[13] E. Brewe, L. Kramer, and G. O'Brien, "Modeling instruction: Positive attitudinal shifts in introductory physics measured with CLASS," Physical Review Special Topics-Physics Education Research, vol. 5, no. 1, pp. 013102-1013102-5, 2009, doi: 10.1103/PhysRevSTPER.5.013102.

[14] A. Elby, "Another reason that physics students learn by rote," American Journal of Physics, vol. 67, no. 7, pp. S52-S57, June 1999, doi: 10.1119/1.19081.

[15] B. A. Lindsey, L. Hsu, H. Sadaghiani, J. W. Taylor, and K. Cummings, "Positive attitudinal shifts with the physics by Inquiry curriculum across multiple implementations," Physical Review Special Topics-Physics Education Research, vol. 8, no. 1, pp. 010102-1-010102-8, 2012, doi: 10.1103/PhysRevSTPER.8.010102.

[16] A. Traxler and E. Brewe, "Equity investigation of attitudinal shifts in introductory physics," Physical Review Special Topics-Physics Education Research, vol. 11, no. 2, pp. 020132-1-020132-7, 2015. 10.1103/PhysRevSTPER.11.020132.

[17] P.N. Vilia, A.A. Candeias, A. S. Neto, M. da G. Franco, and M. Melo, "Academic Achievement in physicschemistry: The predictive effect of attitudes and reasoning abilities," Frontiers in Psychology, vol. 8, pp. 1-9, Jun. 2017, doi: 10.3389/fpsyg.2017.01064.

[18] W. K. Adams, et al., "A new instrument for measuring student beliefs about physics and learning physics: The Colorado Learning Attitudes about Science Survey," Physical Review Special Topics- Physics Education Research, vol. 2, no. 1, pp. 010101-1-010101-14, 2006, doi: 10.1103/PhysRevSTPER.2.010101. 
[19] K. K. Perkins, W. K. Adams, S. J. Pollock, N. D. Finkelstein, and C. E. Wieman, "Correlating student beliefs with student learning using the Colorado learning attitudes about science survey," in AIP Conference Proceedings, California, vol. 790, no. 1, 2005, pp. 61-64, doi: 10.1063/1.2084701.

[20] M. Milner-Bolotin, T. Antimirova, A. Noack, and A. Petrov, "Attitudes about science and conceptual physics learning in university introductory physics courses," Physical Review Special Topics- Physics Education Research, vol. 7, no. 2, pp. 020107-1-020107-9, 2011, doi: 10.1103/PhysRevSTPER.7.020107.

[21] J. D. Bransford, A. L. Brown, and R. R Cocking, "Brain, Mind, Experience, and school," in How People Learn. Washington DC: The National Academies Press, 2002, doi: 10.17226/9853.

[22] V. K. Otero and K. E. Gray, "Attitudinal gains across multiple universities using the Physics and Everyday Thinking curriculum," Physical Review Special Topics-Physics Education Research, vol. 4, no. 2, pp. 020104-1-020104-7, 2008, doi: 10.1103/PhysRevSTPER.4.020104.

[23] E. Brewe, Traxler, J. D. L Garza, and L. H. Kramer, "Extending positive CLASS results across multiple instructors and multiple classes of Modeling Instruction," Physical Review Special Topics-Physics Education Research, vol. 9, no. 2, pp. 020116-1-020116-10, 2013, doi: 10.1103/PhysRevSTPER.9.020116.

[24] P. Zhang, L. Ding, and E. Mazur, "Peer Instruction in introductory physics: A method to bring about positive changes in students' attitudes and beliefs," Physical Review Special Topics-Physics Education Research, vol. 3, no. 1, pp. 010104-1-010104-9, 2017, doi: 10.1103/PhysRevPhysEducRes.13.010104.

[25] C. Williams, "Research methods," Journal of Business \& Economic Research, vol. 5, no. 3, pp. 65-72, 2007, doi: 10.19030/jber.v5i3.2532.

[26] E. F. Redish, J. M. Saul, and R. N. Steinberg, "Student expectations in introductory physics," American Journal of Physics, vol. 66, no. 3, pp. 212-224, 1998, doi: 10.1119/1.18847.

[27] D. Kaur and Y. Zhao, "Development of physics attitude scale (PAS): An instrument to measure students' attitudes toward physics," Asia-Pacific Education Researcher, vol. 26, no. 5, pp. 291-304, 2017, doi: 10.1007/s40299-0170349-y.

[28] K. Salta and C. Tzougraki, "Attitudes toward chemistry among 11th grade students in high schools in Greece," Science Education, vol. 88, no. 4, pp. 535-547, 2004, doi: 10.1002/sce.10134

[29] J. Cohen, Statistical power analysis for the behavioral sciences, 2nd ed. Hillsdale, NJ: Erlbaum, 1988.

[30] R. George, "Measuring change in students' attitude toward science over time: An application of latent variable growth modeling," Journal of Science Education and Technology, vol. 9, no. 3, pp. 213-225, 2000, doi: 10.1023/A:1009491500456.

[31] N. Reid and E. A. Skryabina, "Attitudes towards Physics," Research in Science and Technological Education, vol. 20, no. 1, pp. 67-81, 2002, doi: 10.1080/02635140220130939.

[32] A. Mason and C. Singh, "Surveying graduate students' attitudes and approaches to problem solving," Physical Review Special Topics- Physics Education Research, vol. 6, no. 2, pp. 020124-1-020124-16, 2010, doi: 10.1103/PhysRevSTPER.6.020124.

[33] R. Moll and M. Milner-Bolotin, "The effect of interactive lecture experiments on student academic achievement and attitudes towards physics," Canadian Journal of Physics, vol. 87, no. 8, pp. 917-924, 2009, doi: 10.1139/P09-048.

[34] D. Uwizeyimana, L.L Yadav, T. Musengimana, and J. Uwamahoro, "The impact of teaching approaches on effective physics learning: an investigation conducted in five Secondary Schools in Rusizi District, Rwanda," Rwandan Journal of Education, vol. 4, no. 2, pp. 4-14, 2018. [Online]. Available: https://www.ajol.info/index.php/rje/article/view/175117.

[35] A. Mbonyiryivuze, L. L. Yadav, and M. M. Amadalo, "Students' conceptual understanding of electricity and magnetism and its implications: A review," African Journal of Educational Studies in Mathematics and Sciences, vol. 15, no. 2, pp. 55-67, 2019. [Online]. Available: https://www.ajol.info/index.php/ajesms/article/view/192016.

[36] R. K. Thornton and D. R. Sokoloff, "Learning motion concepts using real-time microcomputer-based laboratory tools," American Journal of Physics, vol. 58, no. 9, pp. 853-867, 1990, doi: 10.1119/1.16350.

[37] S. P. Bates, R.K. Galloway, C. Loptson, and K. A. Slaughter, "How attitudes and beliefs about physics change from high school to faculty," Physical Review Special Topics- Physics Education Research, vol. 7, no. 2, pp. 020114-1020114-8, 2011, doi: 10.1103/PhysRevSTPER.7.020114.

[38] N. Balta, A. J. Mason, and C. Singh, "Surveying Turkish high school and university students' attitudes and approaches to physics problem-solving," Physical Review Physics Education Research, vol. 12, no. 1, pp. 010129-1010129-16, 2016, doi: 10.1103/PhysRevPhysEducRes.12.010129.

[39] G. Duda and K. Garrett, "Blogging in the physics classroom: A research-based approach to shaping students' attitudes toward physics," American Journal of Physics, vol. 76, no. 11, pp. 1054-1065, 2008, doi: 10.1119/1.2967707.

[40] B. R. Wilcox and H. J. Lewandowski, "Students' epistemologies about experimental physics: Validating the Colorado Learning Attitudes about Science Survey for experimental physics," Physical Review Physics Education Research, vol. 12, no. 1, pp. 010123-1-010123-11, 2016, doi: 10.1103/PhysRevPhysEducRes.12.010123.

[41] L. Lising and A. Elby, "The impact of epistemology on learning: A case study from introductory physics," American Journal of Physics, vol. 73, no. 4, pp. 372-382, 2005, doi: 10.1119/1.1848115. 